\title{
Tobacco use among working adolescents and high school students in Turkey: evaluating the effect of the national tobacco control policy
}

\author{
Erkan Çakır ${ }^{1 \oplus}$, Hakan Yazan ${ }^{1 \oplus}$, Nazlı Karacabey ${ }^{2 \oplus}$, Ahmet Hakan Gedik ${ }^{1 \oplus \text {, }}$ \\ Ali Özdemir ${ }^{3 \oplus}$, Nezih Varol ${ }^{4 \oplus}$, Fazilet Karakoç ${ }^{5 \oplus}$, Refika Ersu ${ }^{5 \oplus}$, Bülent Karadağ ${ }^{5 \oplus}$, \\ Elif Dağ $11^{50}$
}

${ }^{1}$ Division of Pediatric Pulmonology, ${ }^{2}$ Department of Pediatrics, Bezmialem Vakif University Faculty of Medicine, Istanbul; ${ }^{3}$ Division of Pediatric Pulmonology, Mersin Children's Hospital, Mersin; ${ }^{4}$ Marmara University Faculty of Health Education, İstanbul; ${ }^{5}$ Division of Pediatric Pulmonology, Marmara University Faculty of Medicine, İstanbul, Turkey.

\begin{abstract}
Background. In our previous published study conducted in 2006 before the national tobacco control program (NTCP), we found that working adolescents (WA) more frequently consumed cigarettes than high school students (HSS). The objective of the present study was to compare the smoking status of WA and HSS before and after the NTCP.

Methods. A questionnaire including questions about the participant's socio-economic level and smoking status was administered.

Results. There were 668 subjects in the 2006 study and 869 subjects in the 2015 study. When we compared the 2015 results with the 2006 study, while there was a significant decline in the ever smokers $(p<0.001)$, there was no difference in current smokers in both the female and male WA groups. In the HSS group, there was a significant decline in ever smokers $(\mathrm{p}<0.01)$, for both females and males. While there was a significant decline in current female smokers $(\mathrm{p}=0,002)$, no significant decrease was found in current male smokers $(p>0.05)$ in the HSS group.

Conclusions. After the initiation of the NTCP, we have not seen a reduction in the smoking rates of both female and male WA and male HSS. The NTCP should particularly focus on the adolescent group in Turkey.
\end{abstract}

Key words: tobacco, adolescents, tobacco control.

Tobacco smoking is the most important avoidable public health problem in the world. Smoking causes pulmonary and cardiovascular complications. ${ }^{1}$ With public awareness of hazardous toxic effects of tobacco consumption, smoking has declined, especially in high income countries, but low and middle income countries remain the targets of the tobacco industry. Turkey is one of the leading tobacco consumer countries in the world. ${ }^{2}$ In

$凶$ Erkan Çakır

erkancakir1@yahoo.com

Received 11th February 2021, revised 24th March 2021, accepted 25th March 2021.
2006, the Turkish Government implemented a smoke-free legislation (Law No: 4207/5727) and a comprehensive tobacco control plan that banned smoking in closed public areas, a ban on smoking advertising through any media and or communication platform, pictorial health warnings about smoking, and prohibition of the sale of tobacco products to individuals under 18 years of age. This campaign has been in force continuously since then. It is estimated that there has been a $13 \%$ decline in smoking consumption nationwide following the implementation of these regulations and the resulting heightened public awareness of the harmful health effects of tobacco smoking. ${ }^{1}$ 
It is well known that smoking addiction starts at an early age. ${ }^{3}$ The young population are at risk for a longer exposure to the toxic effects of tobacco smoking. There is limited data, regarding both the smoking status of adolescents and the effect of the tobacco control policy on smoking consumption. In our previous published study conducted in 2006 before the national tobacco control program was instituted, we found that working adolescents (WA) more frequently consume cigarettes and were exposed to second-hand (cigarette) smoking at home more frequently than non-worker high school students (HSS). ${ }^{4}$ The objective of the present study was to compare the smoking status of WA and HSS and to evaluate the effect of the national tobacco control policy on these groups.

\section{Material and Methods}

Both studies, in 2006 and 2015, were conducted in a district of Istanbul, which is populated with low to middle income people. The same target population and area were chosen from WA and HSS in both the earlier and later study. The WA group were students at a Vocational Training Center which offers apprenticeship training. The apprentices study at school once a week while they work during the rest of the week. Their training areas at the center include hairdressing, lathe-finishing, motor repair and textile manufacture. The HSS group was from a high school, which is located in the same district.

The study was approved by the local ethics committee of the Bezmialem Vakif University (Number: 36/12, date: 08.04.2013). Additionally, permissions were obtained from the Kartal Province National Educational Directorate, the management of the high school, and the parents of the participants. All study participants were informed about the study and its objectives and signed written consent forms before inclusion in the study. It was explained to the participants that the questionnaire results would be kept according to the principle of confidentiality. The questionnaires in the current study were designed in the same manner as the 2006 study. ${ }^{4}$ A questionnaire included questions about the participant's socio-economic and smoking status. All questionnaires were carried out faceto-face by the same researcher. Participants who had 100 or more cigarettes in their lifetime and currently smoked cigarettes were considered current smokers. Adolescents who had tried at least one cigarette in their lifetime were considered ever smokers. ${ }^{5}$ Smoking at home was defined as existence of an adult who was a current smoker at home.

In this study, we first compared the smoking status of the WA and HSS groups in the 2015 study. Then, we compared the 2006 and 2015 data for the WA and HSS groups with each other.

\section{Statistical analysis}

During the assessment of the study data, we described our numerical parameters with mean and standard deviation values while we investigated the distribution of the categorical measurements by frequency and percentages. An independent samples t-test was used for the evaluation of numerical parameters with normal distribution, and the Mann-Whitney U-test was used for the evaluation of parameters without normal distribution. A chi-square test was used in the univariate assessment of our parameters, also performed classifying numerical parameters. The Pearson chi-square, Fisher's exact chi-square, the Fisher Freeman Hatlon exact chi-square, and Yates correction chi-square tests were used for comparison of qualitative data. The results were evaluated at a $95 \%$ confidence interval and at a significance level of $\mathrm{p}<0.05$. The SPSS for Windows 13.0 and NCSS (Number Cruncher Statistical System) programs were used for the statistical analysis.

\section{Results}

There were 554 participants in the WA group and 244 subjects in the HSS group in the 2015 study versus 353 subjects in the WA group and 315 subjects in the HSS group in the 2006 
study. Table I summarizes the demographic characteristics and smoking status of the participants of the 2015 study. Those who had ever smoked (ever smokers) ( $p<0.001$ ), current smokers $(\mathrm{p}<0.001)$, and smoking exposure at home $(p<0.005)$ were significantly higher in the WA group than HSS group.

Comparison of demographic characteristics and the smoking status of WA in 2006 and in 2015 is shown in Table II. There was no significant difference regarding the median age and gender between the WA groups. While there was a significant decline in the ever smokers ( $p<0.001)$, there was no difference in current smokers for both females and males.
Comparison of demographic characteristics and smoking status of HSS in 2006 and 2015 is shown in Table III. There was a significant decline in ever smokers ( $p<0.01)$, for both females and males. While there was a significant decline in current female smokers ( $\mathrm{p}=0.002)$, no significant decrease was found in current male smokers ( $\mathrm{p}$ $>0.05$ ).

There was no significant difference according to smoking exposure at home between 2006 and 2015 in both groups.

We also evaluated attitudes and behaviors of WA and HSS in 2015 about the smoking bans (Table IV). There were similar views in the two groups.

Table I. Demographic characteristics and smoking status of the participants in 2015.

\begin{tabular}{|c|c|c|c|c|c|c|}
\hline \multirow{3}{*}{ Mean age } & & \multicolumn{2}{|c|}{ Working adolescents $(n=554)$} & \multicolumn{2}{|c|}{ High school students $(n=244)$} & \multirow{3}{*}{$\frac{\mathrm{p}}{>0.05}$} \\
\hline & & \multicolumn{2}{|c|}{$17.67 \pm 1.34$} & \multicolumn{2}{|c|}{$16.54 \pm 0.93$} & \\
\hline & & $\mathrm{n}$ & $\%$ & $\mathrm{n}$ & $\%$ & \\
\hline \multirow[t]{2}{*}{ Gender } & Female & 90 & 16.2 & 114 & 46.7 & $<0.001$ \\
\hline & Male & 464 & 83.8 & 130 & 53.7 & \\
\hline \multirow[t]{3}{*}{ Ever smoker } & Female & 52 & 57.8 & 24 & 21.1 & $<0.001$ \\
\hline & Male & 282 & 60.8 & 43 & 33.1 & $<0.001$ \\
\hline & Total & 334 & 60.3 & 67 & 27.5 & $<0.001$ \\
\hline \multirow[t]{3}{*}{ Current smoker } & Female & 35 & 38.9 & 3 & 3.6 & $<0.001$ \\
\hline & Male & 203 & 43.8 & 17 & 13.1 & $<0.001$ \\
\hline & Total & 238 & 43.0 & 20 & 8.2 & $<0.001$ \\
\hline \multicolumn{2}{|l|}{ Smoking at home } & 382 & 69.0 & 143 & 58.6 & 0.005 \\
\hline
\end{tabular}

Table II. Comparison of demographic characteristics and the smoking status of the working adolescents in 2006 and 2015.

\begin{tabular}{|c|c|c|c|c|c|c|}
\hline & & Working & ts, 2006 & Working & nts, 2015 & $\mathrm{p}$ \\
\hline Median age (yea & & & & & & $>0.05$ \\
\hline & & $\mathrm{n}$ & $\%$ & $\mathrm{n}$ & $\%$ & \\
\hline Gender & Female & 54 & 15.3 & 90 & 16.2 & $>0.05$ \\
\hline & Male & 299 & 84.7 & 464 & 83.8 & \\
\hline Ever smoker & Female & 38 & 70.3 & 52 & 57.8 & 0.001 \\
\hline & Male & 236 & 78.9 & 282 & 60.8 & 0.001 \\
\hline & Total & 274 & 77.6 & 334 & 60.3 & 0.001 \\
\hline Current smoker & Female & 19 & 35.1 & 35 & 38.9 & $>0.05$ \\
\hline & Male & 130 & 43.4 & 203 & 43.8 & $>0.05$ \\
\hline & Total & 149 & 42.2 & 238 & 43.0 & $>0.05$ \\
\hline Smoking at hom & & 266 & 75.4 & 382 & 69 & $>0.05$ \\
\hline
\end{tabular}


Table III. Comparison of demographic characteristics and the smoking status of the high school students in 2006 and 2015.

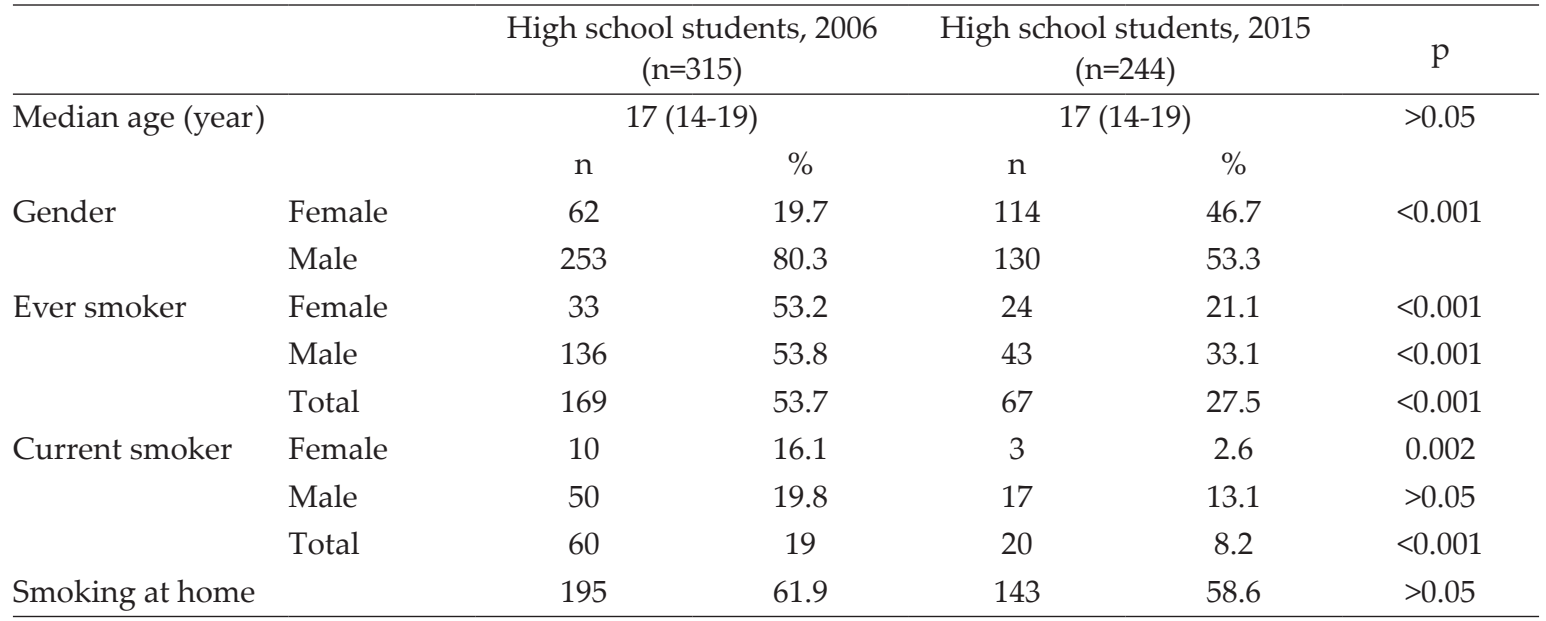

Table IV. Knowledge and behavior of students concerning the smoking ban.

\begin{tabular}{|c|c|c|c|c|}
\hline & & $\begin{array}{l}\text { Working } \\
\text { adolescents }\end{array}$ & $\begin{array}{l}\text { High school } \\
\text { students }\end{array}$ & $\mathrm{p}$ \\
\hline & & $\%$ & $\%$ & \\
\hline Has anyone quitted smoking in your family after the ban? & Yes & 23 & 30 & $>0.05$ \\
\hline Do you support the ban & Yes & 90 & 91 & $>0.05$ \\
\hline Should the government take action against smoking? & Yes & 89 & 88 & $>0.05$ \\
\hline Is passive smoking harmful? & Yes & 89 & 89 & $>0.05$ \\
\hline Are smoking bans enough? & No & 57 & 52 & $>0.05$ \\
\hline $\begin{array}{l}\text { Do you know that there are penalties for businesses that allow } \\
\text { smoking? }\end{array}$ & Yes & 99 & 93 & $>0.05$ \\
\hline $\begin{array}{l}\text { Do you know that if a person sells cigarettes to someone under } \\
18 \text { they can be imprisoned? }\end{array}$ & Yes & 56 & 54 & $>0.05$ \\
\hline Do you know that tobacco companies cannot advertise? & Yes & 80 & 80 & $>0.05$ \\
\hline $\begin{array}{l}\text { Do you know that waste such as cigarette butts cannot be } \\
\text { thrown? }\end{array}$ & Yes & 54 & 47 & $>0.05$ \\
\hline
\end{tabular}

\section{Discussion}

In this study, the smoking behavior of WA and HSS were evaluated after the national tobacco control policy went into effect. There was no decline in the current smoker ratios of the WA before and after the national smoking policy was initiated. In the HSS, the current smoker ratio declined in girls but not in boys. As in 2006, the WA smoking ratio was higher than that for HSS in 2015.

Smoking most often starts in adolescence; thus, to prevent smoking, interventions should be done in this period. It is estimated that smoking varies between $13.8 \%$ and $28 \%$ for the HSS group in different parts of the world. According to the Global Youth Tobacco Survey (GYTS) study that was conducted between 2013-2014 and included forty-five countries, the ratio of current smokers of high school age varies between $1.7 \%$ to $28.9 \%$ (Kazakhstan $1.7 \%$ and Timor-Leste $28.9 \%)^{6}$

In 2006 in Turkey, a school-based survey of 15,957 students between the ages of 13 and 15 years was conducted, and it was established 
that around one third of students had already tried smoking, and $10 \%$ were current smokers. ${ }^{7}$ In most studies, current smokers were predominantly male. However, a study from the Turkish city of Izmir showed that females were slightly higher current smokers, but that was not statistically significant ( F/M: $23.7 \%$ \& $22.7 \%)^{8}$

There are a few studies regarding the smoking status of WA in the literature. The frequency of smoking of WA was found to be significantly higher than that of HSS in Turkey (ranging between $21.7 \%$ and $50.5 \%$ ) as in our study.,9,10,11 Similar ratios were seen in a few studies in other countries. ${ }^{12,13}$

The National Tobacco Law is the leading regulation along with other comprehensive smoke-free environmental campaigns in Turkey. There are not enough studies that compare the smoking status before and after National Tobacco Policy was instituted. In our study, we compared the smoking status of both WA students and HSS students before and after the National Tobacco Law was initiated. While there was a significant reduction in the ever and current smoker ratios in the high school girl group, there was no reduction in current smoker ratios in high school boys and both female and male working adolescents. Our study is the only study in Turkey that compares the smoking ratios in the same population before and after the smoking ban. In the literature, we found two studies that evaluated the smoking ratios before and after the smoking ban in Turkey, but the study design and the groups were different from our study. The study population of these two studies were 10th grade high school students but not in the same area. Ever smoker ratios were evaluated in these studies. There was a significant decrease in the ever smoker ratio (the 2005 study, 37\% and the 2013 study, $24.4 \%$ ). Current smokers were not evaluated in these studies. ${ }^{14,15} \mathrm{~A}$ study of adults that evaluated tobacco control activities in Turkey found a $13 \%$ reduction in current smokers from 2006 to 2013 (31.7\% and $27.1 \%) .{ }^{16}$
There are a few studies in the literature from around the world that compare the smoking ratio in HSS. In a study from Argentina, after the implementation of anti-smoking regulations in 2011, the overall proportion of youths aged approximately 13-15 years who reported ever smoking a cigarette declined from 52\% in 2007 to $41.9 \%$ in $2012 .{ }^{17}$

To the best of our knowledge, there is no study comparing WA before and after smoking bans either in Turkey and the world at large; thus, our study may be the first one.

We also evaluated smoking exposure in both groups, comparing 2006 and 2015. Smoking exposure at home was reduced from 2006 to 2015 , but it was not statistically significant. Bilir et al. ${ }^{16}$ assessed second hand smoke in various places before and after the ban. In Bilir's study, after the National Tobacco Policy was instituted, exposure to second hand smoke reduced in restaurants (55.9\% and $12.9 \%)$, homes $(56.3 \%$ and $38.3 \%)$, workplaces (37.3\% and $15.6 \%)$, public transportation $(16.5 \%$ and $10.4 \%)$, and government buildings ( $11.3 \%$ and $6.5 \%)$.

In this study, we also evaluated the knowledge and behavior of adolescents in terms of the smoking ban in 2015. Both the WA and HSS groups had similar views about the smoking ban, and most of the adolescents supported the ban.

In conclusion, after the National Tobacco Control Program was instituted, we did not see a reduction in the smoking ratios of working adolescents and high school boys. Therefore, the National Tobacco Control program was found to be less effective than expected, especially in the adolescent group. New studies encompassing a large area evaluating smoking status after the ban are needed. New policies against smoking are also needed to reduce the smoking ratios, especially in adolescents.

\section{Author contribution}

The authors confirm contribution to the paper as follows: study conception and design: EÇ, 
FK, RE, BK, ED; data collection: BNK, AHG; analysis interpetation of results: EÇ, AÖ, HY, $\mathrm{NV}$; draft manuscript preperation: EÇ, AÖ, HY. All authors reviewed the results and approved the final version of the manuscript.

\section{Ethical approval}

The study was approved by the local ethics committee of the Bezmialem Vakif University (Number: 36/12, date: 08.04.2013).

\section{Source of funding}

The authors declared that this study has received no financial support.

\section{Conflict of interest}

The authors declare no conflict of interest.

\section{REFERENCES}

1. Bozkurt AI, Sahinoz S, Ozcirpici B, et al. Patterns of active and passive smoking and associated factors, in the South-east Anatolian Project (SEAP) region in Turkey. BMC Public Health 2006; 6: 15.

2. World Health Organization. Enforcing bans on tobacco advertising, promotion and sponsorship. Report on the global tobacco epidemic -2013. Available at: https://www.who.int/publications/i/ item/9789241505871 2013 (Accesssed on November 2, 2019).

3. Arabi Z. An epidemic that deserves more attention: epidemiology, prevention, and treatment of smokeless tobacco. South Med J 2007; 100: 890-894.

4. Cakir E, Karakoc F, Ersu R, Karadag B, Varol N, Dagli E. Comparing the smoking status of working adolescents with adolescents enrolled in high school in Turkey. Pediatr Allergy Immunol Pulmonol 2013; 26: $32-34$

5. National Center for Health Statistics. Available at: https://www.cdc.gov/nchs/nhis/tobacco/tobacco_ glossary.htm (Accessed on May 16, 2021).
6. D'Angelo D, Ahluwalia IB, Pun E, Yin S, Palipudi K, Mbulo L. Current cigarette smokers, access, and purchases from retail outlets among students aged 13-15 years global youth tobacco survey, 45 countries, 2013 and 2014. MMWR Morb Mortal Wkly Rep 2016; 65: 898-901.

7. Erguder T, Soydal T, Ugurlu M, Cakir B, Warren CW. Tobacco use among youth and related characteristics, Turkey. Soz Praventivmed 2006; 51: 91-98.

8. Goksel $\mathrm{T}$, Cirit $\mathrm{M}$, Bayındır Ü. İzmir ili lise öğrencilerinin sigara alışkanlığını etkileyen faktörler. Toraks Dergisi 2001; 3: 49-53.

9. Erbaydar T, Lawrence S, Dagli E, Hayran O, Collishaw NE. Influence of social environment in smoking among adolescents in Turkey. Eur J Public Health 2005; 15: 404-410.

10. Alikasifoglu M, Erginoz E, Ercan O, Uysal O, Kaymak-Albayrak D, Ilter O. Cigarette smoking among Turkish high school students. J Adolesc Health 2002; 30: 7-8.

11. Kutlu R. Meram çıraklık okulu öğrencilerinde sigara kullanma sıklığı. TSK Koruyucu Hekimlik Bülteni 2006; 5: 424-433.

12. Warren CW, Jones NR, Peruga A, et al; Centers for Disease Control and Prevention (CDC) Global youth tobacco surveillance, 2000-2007. MMWR Surveill Summ 2008; 57: 1-28.

13. Fagan P, Stoddard AM, Hunt MK, Frazier L, Girod $\mathrm{K}$, Sorensen $\mathrm{G}$. The feasibility of evaluating a tobacco control intervention for working youth. Tob Control 2003; 12(Suppl 4): IV34-IV39.

14. Ögel K, Taner S, Eke CY. Onuncu sınıf öğrencileri arasında tütün, alkol ve madde kullanım yaygınlığı: İstanbul örneklemi. Bağımlılık Dergisi 2006; 7: 18-23.

15. Evren C, Ogel K, Demirci A, Evren B, Yavuz BG, Bozkurt M. Prevalence of lifetime tobacco, alcohol and drug use among 10th grade students in İstanbul. Bull Clin Psychopharmacol 2014; 24: 201-210.

16. Bilir N, Ozcebe H. Tobacco control activities in Turkey. Turk J Public Health 2013; 11: 96-103.

17. Konfino J, Ferrante D, Goldberg L, Caixeta R, Palipudi KM, Centers for Disease Control and Prevention Tobacco use among youths-Argentina, 2007 and 2012. MMVR Morb Mortal Wkly Rep 2014; 63: $588-590$. 